\title{
The Meaning and Use of the Modals CAN and MAY in English Contract Law Texts
}

\begin{abstract}
This paper presents the results of an analysis of the English modals CAN and MAY in four text types covering the domain of Contract Law. These results show a distinct difference between the two modals, which is interesting because the meaning and use of CAN and MAY is generally taken to be more blurred than it is the case here. The meaning and use of the modals is analysed and compared on the basis of logico-semantic and pragmatic parameters briefly introduced in the paper. The analysis is part of a major contrastive analysis of the meaning and use of the Danish and English modals.
\end{abstract}

The central English modals have been the subject of a great number of linguistic studies in recent years 1 , and the same goes for English and American legal discourse ${ }^{2}$, but until now there has not been any analysis published which has combined the two and focussed on the meaning and use of the modals in English legal discourse. In this paper I will present the results of such an analysis, viz. the meaning and use of the modals CAN and MAY in the four text types 1. Statutes, rules and regulations, 2. Travaux préparatoires 3 , 3. Judgments, and 4 . Contracts in the corpus of Contract Law.

$1 \quad$ Notably Coates, 1983; Leech, 1987; Palmer, 1986, 1988, 1990, and Perkins, 1983 as well as Davidsen-Nielsen's 1990 constrastive study of tense and mood in English and Danish.

2 Cf. e.g. Crystal \& Davy, 1969; Danet, 1980, 1985; Kurzon, 1986, 1989; Levi, 1986; and Maley, 1987.

3 The labels for the three of the text types should be self-explanatory. As far as text type II is concerned, I stick to the terminology introduced by the corpus compilation project team even though it is not an especially felicitous term seen from the point of view of English alone. Travaux préparatoires is a cover term for working papers, report from law commissions and similar texts. 
These results are all part of a major contrastive project on the meaning and use of the modals in English and Danish legal discourse ${ }^{4}$, cf. Lauridsen (in preparation).

The analysis of the English modals which will be presented in the following distinguishes itself in at least three different ways: First of all, it is not an analysis of a set of linguistic items (in this case the modals) in general, but an analysis of the conditions under which we find these items in specifically defined parts of legal discourse and the study is thus a contribution to the analysis and description of one of the many so-called languages for special purposes (LSPs), a branch of linguistic research which has obtained an increasing amount of interest in the last couple of decades.

Secondly, it extracts its data from a large text corpus, viz. the corpus of Contract Law. Previous analyses of legal discourse have generally been based on relatively small amounts of data even though they have adopted an empirical approach, and the machine-readable text corpus which has so far been available for large-scale linguistic analysis (that is, the LOB corpus for British English) only comprises a few text samples from the domain of legal discourse $^{5}$. To the best of my knowledge, there are no other text corpora of one million words or more available within the domain of legal discourse, and analyses using data from the contract law corpora of each one million words are therefore unique because of their solid database.

Finally, the study of the English modals is potentially contrastive because there are two other corpora of contract law (French and Danish) which have been compiled according to the same principles as those governing the English corpus and which may therefore supply comparable data. Further, it is potentially contrastive because the analysis of the modals is carried out within the framework of a semantic taxonomy of modality which is not language specific and which may therefore also be applied to

\footnotetext{
4 The project has been partly financed by the Danish Research Council for the Humanities, 1991.

5 In the so-called LOB corpus, cf. Johansson, Stig et al. (1978) we find two samples under category H (Miscellaneous), subcategory Government documents/Acts and Treaties, and three samples under category $\mathbf{J}$ (Learned and scientific writings), subcategory Political science, law, education.
} 
analyses of modal expressions in other languages or even other analyses of English modals, for instance with data from other domains or text types.

\section{The semantic taxonomy}

The semantic taxonomy used in the categorization of the modals is a further development of what I have described previously, cf. Lauridsen (1988) and (in print). Modality is defined as a general, not language-specific category which may be expressed by means of different grammatical categories in the individual languages: for English in the oblique moods of the verb phrase (imperative and the rudimentary subjunctive plus certain uses of the indicative), modal verbs, tense, and finally it may be lexicalized or expressed by means of certain syntactic structures such as conditional clauses 6 .

The modal categories which constitute the semantic taxonomy are regarded as imprecise, Boolean categories; their definition is based on the logical concept of possible worlds and the classic operators of modal logic, possibility and necessity.

The concept of possible worlds may be defined as the idea that things might be or might have been other than they actually are or were, cf. Rescher (1979). A proposition may thus be true in a given world (real or imagined), but false in another. Moreover, the concept may cover the situation in a given world, for instance the real world, at different points in time, cf. Prior (1957).

(1) The hearing is at $10 o^{\prime}$ clock

(2) The hearing may be at 10 o'clock

(3) The hearing must be at 10 o'clock

In the examples above, the factual example (1) without a modal verb expresses that its propositional content is true in the real world; (2) with the modal may expresses that there is a possible world in which the propositional content is true, and (3) with the modal must that the propositional content is true in all possible worlds. The concept of possible worlds is thus used in this study as a prerequisite for the semantic categorization of modality in order to show that facts of the real world may or must be different.

6 Cf. Perkins, 1983. 
In modal logic, the two so-called modal operators possibility and necessity are interrelated as follows:

(4) $\operatorname{pos} p=$ non nec non $p$ nec $p=$ non pos non $p$

The abbreviation pos signifies the modal operator of possibility, and nec that of necessity, $p$ is the proposition that follows the modal expression, in other words, the whole utterance/sentence except for the modality marker, in this case the modal verb. The formula is to be read as follows: "If it is possible that $p$, it is not necessary that non- $p$; and if it is necessary that $p$, it is not possible that non- $p "$.

(5) The parties may exclude the doctrine of substantial performance by an

express provision of the contract (I)

(6) The innocent party must have obtained a benefit from the partial performance of an entire contract by the party in

In (5) and (6) the logical operators of possibility and necessity are expressed; may in (5) has the possibility operator among its semantic features and may therefore be paraphrased as "It is possible that $p$ ", where $p$ is "The parties exclude the doctrine of substantial performance by an express provision of the contract". Similarly, must in (6) has the necessity operator among its semantic features and may be paraphrased as "It is necessary (i.e. necessarily the case) that $p$ ", where $p$ is "The innocent party has obtained a benefit from the partial performance of an entire contract by the party in breach".

When we take into consideration the concept of possible worlds as well as the relevant categories of modal logic, modality may thus be understood as the grammaticalization or lexicalization, first, of the speaker's attitude concerning the possibility or necessity of whether a given proposition is true or false (epistemic modality) or, second, of a modal source's attitude concerning the bringing about of a given event or situation (deontic modality). By modal source is understood the person or institution that is the original sender of the modal proposition. Third, modality may be the grammaticalization or lexicalization of the possibility, or necessity of a given characteristic supposed to be inherent in the referent of the noun phrase which constitutes the subject of the modalized expression (dynamic modality).

The distinctions between epistemic and deontic modality and between the modal operators of possibility and necessity are exemplified in table 1: 
$\mathrm{H}$

e

E
P

T

E

M

I

M

O

D

A

L

I

Y ible that he will require a

second hearing") $\mathrm{m}$

a

$\mathrm{y}$

r

e

q

i

r

e

a

S

e

c

o

h

e

a

r

n

g

(

I

$\mathrm{p}$

$\mathrm{O}$ 
H

$\mathrm{m}$

$\mathrm{u}$

s

e

q

u

a

S

e

c

n

$\mathrm{h}$

e

a

r

$\mathrm{n}$

I

i

S

n

e

c he will require a second

hearing") 
$\mathrm{H}$

e

D

E

$\mathrm{O}$

$\mathrm{N}$

$\mathrm{T}$

I

$\mathrm{M}$

$\mathrm{O}$

D

A

I

$\mathrm{T}$

Y ible for him to / He is

allowed to ask for a second

hearing")
$\mathrm{m}$
a
y
a
$\mathrm{S}$
$\mathrm{k}$
f
o
a
S
c
o
h
e
a
n
g
(
I
S
$\mathrm{p}$
O
$\mathrm{s}$ 


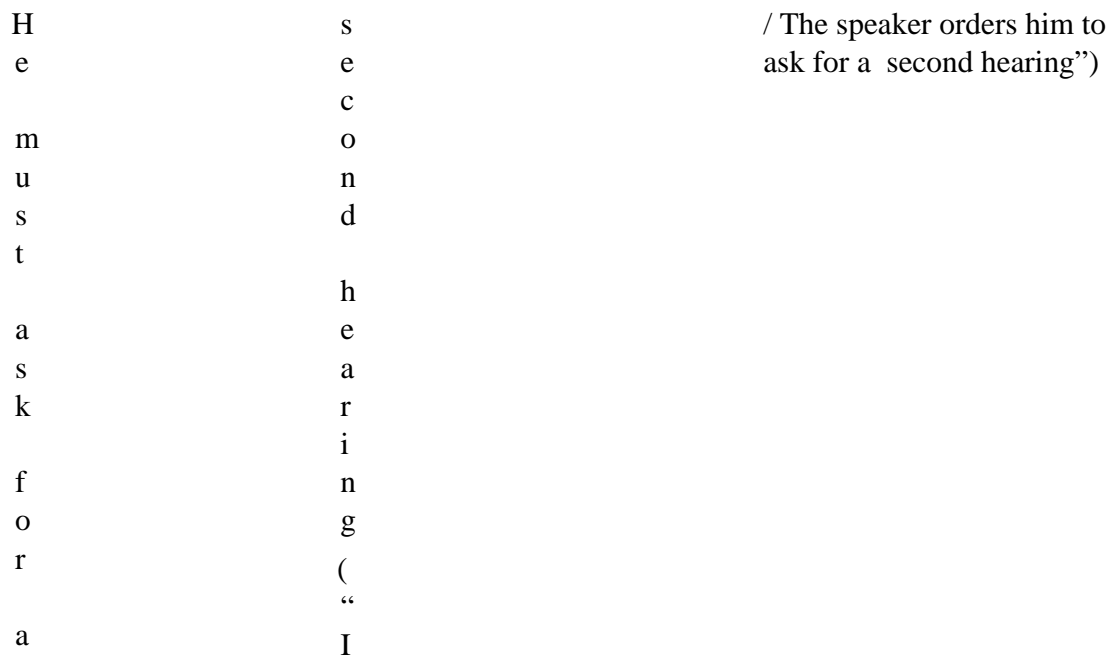

Table 1

The semantic distinction between epistemic and non-epistemic modality is reflected in a range of syntactico-semantic differences between the modals expressing these two subcategories, cf. Lauridsen (1988) and (in print).

In the following, the distinction between the two modal operators possibility and necessity need not concern us any further because the modals CAN and MAY are both expressions of the possibility operator. The distinction between epistemic and non-epistemic modality is highly relevant in the following, whereas the subcategorization of non-epistemic modality into deontic and dynamic modality only plays a minor role.

\section{The modals as implicitly performative verbs}

As it is apparent from the above, it is quite obvious that this study has taken as its starting point the meaning and form of the modals rather than their function. But in the English and American literature on the subject, language pertaining to the legal profession has been considered from various 
functional points of view 7 , notably that of speech act theory, and since parts of such pragmatically oriented descriptions are relevant for the analysis of the modals in legal discourse also, I shall briefly comment on some of them here.

Traditional speech act theory as it was originally outlined by Austin (1962) makes a basic distinction between constative and performative utterances. Constative utterances are statements; their function is to describe some event, process or state-of-affairs, and they (or the propositions expressed) have the property of being either true or false. In contrast to this, performative utterances do not have a truth-value; they are used to do something, rather than to say that something is or is not the case (Lyons (1977:726)). For instance, a speech act of permission (You may ... / I allow you to ... / Go ahead!) or a speech act of order (You must ... / I order you to ... / Come here!) cannot be true or false, but it may be said to be felicitous or infelicitous depending on a set of circumstantial conditions, cf. Lyons (1977:733ff).

Let us consider once more examples (1)-(2) quoted above. (1) will typically be interpreted as a categorical (non-modalized) statement with a truth value, in other words, it may be said to be either true or false. In Austin's terms it is a constative utterance, that is, nonperformative. The modalized (non-categorical) utterance in (2) may be interpreted as constative or performative utterances, depending on its context. Just as it is the case with most modals, may can express epistemic as well as deontic modality; if the context triggers off an epistemic interpretation, the utterance is constative, but if the modal is interpreted as expressing deontic modality, the utterances may be performative. Thus, may in (2) can be paraphrased as a performative utterance as in "I (=the

$7 \quad$ Cf. Danet, 1980, 1985; Kurzon, 1986; Maley, 1987. 
deontic source / a person in authority) permit / allow p" (where $p$ is still the main proposition, in this case, "the hearing be at 10 o'clock"), or it may be paraphrased as a non-performative (constative) utterance as in "It is possible (for $X)$ to $p "$.

Austin (1962) made a basic distinction between primary and explicitly performative utterances; the latter contained an explicitly performative verb such as allow and permit, whereas the former did not (cf. also Lyons (1977:728ff)). Thus, Come in! would be a primary performative utterance, whereas I allow / permit you to come in would be an explicit performative. In a certain sense, performative utterances where the performative element is one of the modals under investigation in this study, may be said to be somewhere on a scale between primary performatives and explicit performatives as far as directness of the performative element is concerned. With this in mind recent studies, cf. e.g. Kurzon (1986), labels the modals in this function implicitly performative verbs, and I shall adopt this term in the following 8 .

As it appears from the discussion of (1)-(2) above, the epistemic modals do not occur as implicitly performative verbs, which is obviously due to the fact that epistemic modals evaluate the truth value of the main proposition and can therefore not be said to be performing an event in the same sense as it is the case with the deontic modals. The deontic modals, on the other hand, often occur as implicit performatives.

Whether utterances containing a deontic modal are meant to be interpreted as constative or performative

8 After the publication of Austin (1962), the problems and further development of his theories have been widely discussed within various branches of linguistics. Any discussion of this falls outside the scope of this study, however; for an overview, cf. Lyons (1977: chapter 16). What I need for my purposes is the distinction between constative and performative utterances exemplified above. 
depends on the linguistic context in close connection with the real-world situation in which the utterance occurs, and a full interpretation is only possible if one takes into consideration the linguistic as well as the non-linguistic elements of the utterance. The situational context relevant for the interpretation of the modals as implicitly performative or non-performative verbs is first and foremost the sender-receiver relations, and since these are to a very large extent institutionalized in the text types under investigation here, it becomes relatively simple to account for them.

In the following the sender - receiver relations will be included in order to account for the semantic and functional distinction between CAN and MAY, both of them modals expressing the possibility operator. However, further elaboration of this falls outside the scope of this paper.

\section{Analysis of the modals CAN and MAY in the Contract Law texts}

Below the two modals of possibility will be analysed in turn whereupon they will be compared semantically and functionally.

\subsection{Analysis of CAN}

In text type I (Statutes, rules and regulations) of the corpus there are only a few examples with CAN, all of them of the kind exemplified in (7)-(9):

(7) An act to impose further limits on the extent to which under the law of England and Wales and Northern Ireland civil liability for breach of contract or for negligence or other breach of duty, can be avoided by means of contract terms and otherwise, and under the law of Scotland civil liability can be avoided by means of contract terms (I

All the examples with CAN in text type I express nonperformative root possibility. I have chosen the term root 
possibility in stead of trying to distinguish between deontic and dynamic possibility because in a lot of instances it is a question of interpretation whether one would classify a given example with CAN as one or the other. Even though there are clear-cut examples, especially if the modal occurs in a context which is lexically and/or syntactically marked as expressing one specific semantic subcategory, it is very often the case that CAN is most adequately interpreted as belonging to the zone where the two imprecise semantic subcategories overlap.

In text type I CAN only occurs with a passive in the following main proposition. It should be noted that the interpretive paraphrase of such examples must necessarily introduce an $\underline{X}$ for whom (which) it is possible to carry out the event expressed by the main proposition, thus in example (7) above "It is possible for $X$ to avoid further limits on the extent (...) by means of contract terms (...)". Such examples are constative, that is, not performative utterances.

(8) A person cannot by reference to any contract term or to a notice given to persons generally or to particular persons exclude or restrict his liability for death or personal injury resulting from negligence (I)

(9) As against a person dealing as consumer, liability in respect of the goods' correspondence with description or sample, or their quality or fitness for any particular purpose, cannot be excluded or restricted by reference to any such term (I)

In examples like (8) and (9) it is the referent of the subject noun phrase in the active clause for whom (which) it is (not) possible to carry out the event expressed by the main proposition; thus, e.g. in (8), "It is not possible for a person by reference (...) to exclude or restrict his liability (...)". As it is seen here, it is the modal proposition of possibility which is negated in cases where CAN expresses root possibility. 
(10) In these circumstances the party who alleges and is able to prove the error in the written contract can obtain from the court an order of rectification

(11) An effect similar to that of merger in a deed can be achieved by an a prior oral agreement (II) If it is clear that the parties agreed oral terms additional to those which they wrote down, the court can analyse the situation as being a contract and

collateral contract rather than a single contract made partly orally

The position under the present law can be summarised as follows (II)

In text type II (Travaux préparatoires) there are quite a few examples with CAN. In (10) and (11) it expresses root possibility, in (10) followed by an active verb phrase expressing the event of the main proposition ("It is possible for the party who (...) to obtain (...)") and in (11) followed by a passive verb phrase ("It is possible for $X$ to achieve an effect similar (..)"). (12) and (13) again demonstrate the problematic distinction between deontic and dynamic possibility: is it "It is possible for the court to analyse (...)" or "The court is able to analyse (...)"? And is it "It is possible for $X$ to summarise the position (...)" or " $X$ is able to summarise (...)? As far as I can see, the question is immaterial here because even though it is certainly possible in theoretical terms to define the semantic distinction between these two subcategories, the data available clearly show that most examples are not prototypical members of either of the two semantic subcategories, but are found in the zone where the two imprecise categories overlap. and partly in writing: ...) (II) 

defects in the present law and that uncertainty can arise in some situations (...) the general approach of the present law by and large provides an

Although CAN does not usually express epistemic modality in its present tense form 9 , there are a few examples where the semantic interpretation seems to indicate a certain ambiguity between epistemic and root possibility; one of these is (14). An interpretation like "It is possible that uncertainty arises (...)" actually seems more likely than a non-epistemic reading, especially because the subject noun phrase is non-referential and the noun denotes an abstract entity; an interpretation like "It is possible for uncertainty to arise (...)" thus seems very awkward indeed. This, once again, only underscores the fact that these semantic subcategories certainly consist of prototypical members, but that the majority of my data are to be regarded as nonprototypical rather than prototypical elements in the semantic subcategories and therefore often occur in contexts where their relation to a specific semantic subcategory is indeterminate.

(15) Where the end product is worth more than the cost of the services there should be an upper limit so that the party in breach cannot be better off as a result of partial performance than he would have been had he (...) This is because there has been no total failure of consideration, and money paid cannot be recovered on a partial failure of consideration (II) recover possession Under the Hire Purchase Act 1965 the lender cannot on the hirer, which has not been until he has served a notice of default applied not only to In a strictly logical sense, if the parol evidence rule writing which, although purporting does not fulfil some legal requirement and (...) (II) 
(15)-(18) are examples of CAN in negated clauses. In (15)(17) it definitely expresses root possibility, and it is the modal proposition which is negated. In (15) and (17) the modal is followed by the active voice in the verb phrase expressing the main proposition, in (16) it is followed by the passive. Whereas the other examples are again indeterminate between deontic and dynamic possibility, (17) is an example of dynamic possibility (ability). Such clear examples seem typically to occur where the referent of the subject noun phrase is animate, especially a human being and the verb phrase expressing the event of the main proposition is in the active voice; this is obviously so because dynamic possibility expresses an inherent characteristic in the referent of the subject noun phrase and such characteristics are typically indicated for human beings who are then also the semantic agent of the event expressed by the main verb in the verb phrase.

Finally, in (18) cannot expresses epistemic nonpossibility, that is, the modal proposition is negated. It should be noted that cannot in its epistemic sense may be a negation of epistemic CAN (cf. the above discussion of CAN as an expression of epistemic possibility), or it may be a negation of epistemic MAY (cf. the discussion of may not below). Examples such as these are rare in the data material.

So, in text type II CAN typically expresses root possibility with relatively many examples of indeterminacy between deontic and dynamic possibility and a few examples of indeterminacy between epistemic and nonepistemic (root) possibility. It is not performative and in negated clauses it is the modal proposition which is negated.

In text type III (Judgments) there are again a number of examples where CAN expresses root possibility:

(19) However, counsel for the plaintiff submits that the law will, so far as it can do so by a monetary reward, 
Just as it has been the case in the previous examples with CAN as an expression of root possibility, there is a certain indeterminacy between the two subcategories of root possibility, deontic and dynamic possibility; this is also seen in (20):

(20) it received little So far as I can ascertain, however, until very recently Similar to what was stated about (17) above, the examples where the referent of the subject noun phrase is a human being and the verb phrase in which the modal occurs is in the active voice are the ones most likely to be interpreted as dynamic possibility (ability); thus in (20) "I am able to ascertain (...)". It should finally be noted here that there is a range of examples which express unability as in My Lords, I cannot accept that argument.

(21) Moreover, the criterion of operation in rem hardly matches counsel's first a lease, which operate in personam. It cannot be because, once vested, a lease cannot be divested except by agreement of the parties (III)

Again, it is the modal proposition which is negated in negative clauses; the first cannot in (21) expresses epistemic non-possibility, whereas the second expresses root non-possibility.

(viii) to do all such other acts and things as may be incidental or aforesaid which he may or conductive to any of the matters and powers the Company (IV) can lawfully do as agent for

CAN is only seen in a few examples in text type IV (Contracts) and always in its root possibility sense. It is not performative. In (22) the sequence may or can is an example of what is known as a binomial expression, cf. Gustafsson (1984). A binomial is a sequence of two words which belong to the same form-class, and which are syntactically coordinated and semantically related. 
Binomials are much more frequent in legal discourse than it is the case for English in general; thus a number of what could be called typical legal expressions are binomials, e.g. the following from the promulgation formula: by and with, advice and consent, (Lords) Spiritual and Temporal.

When I consider the occurrences of modals in binomial expression in my data together with Gustafsson's examples, it seems to me that even though the two elements in such expressions are semantically related, they do not express exactly the same. This is also the case for may and can in (22). MAY expresses deontic possibility (permission) and is a report of a performative MAY, cf. below, whereas CAN expresses dynamic possibility (ability), thus the interpretation would be "(...) which he is permitted and able to lawfully do (...)".

There are a few instances of cannot in text type IV; in all of them CAN expresses non-performative root possibility and it is the modal proposition which is negated as in:

(23) "Domestic Relevant Indebtedness" means any Relevant Indebtedness which (a) is denominated and payable in, and cannot at the option of any person become denominated and/or payable in any currency other than,

There are no examples of epistemic non-possibility in text type IV.

In conclusion, the meaning and use of CAN may be summarised as follows: in the text types analysed here, CAN typically expresses root possibility, more often than not the indeterminate zone where deontic and dynamic possibility overlap. There are a few examples in text type II where CAN may be interpreted as expressing epistemic possibility. When a clause including CAN is negated, it is always a negation of the modal proposition, that is, CANNOT expresses non-possibility irrespective of whether it is epistemic or non-epistemic. CAN is not used performatively. the lawful currency of the Kin 


\subsection{Analysis of MAY}

MAY is one of the central modals in legal discourse. In text type I (Statutes, rules and regulations) it is found in examples such as these:

(24) In estimating for the purposes of the foregoing provisions of this section, the amount of any expenses incurred by any party to the contract, the court may, without prejudice to the generality of the said provisions,

(25) A person dealing as consumer cannot by reference to any contract term be made to indemnify another person (whether a party to the contract or not) in respect of liability that may be incurred by the other for negligence or breach of contract, except in so far as

(26) This act may be cited as the Minors' Contracts Act $1987(\mathrm{I})$

In (24)-(26), may expresses root possibility. (24) and (26) are examples of the kind of performative deontic possibility known in the legal profession as discretionary MAY; the legislature is the deontic source that permits the referent of the subject noun phrase in the active clause to carry out, at his discretion, the events expressed by the main propositions; in the case of (24), the court "is permitted, without prejudice (...) include such sum (...)"; in the case of (26) X is "permitted to cite the act (...)".

Even though MAY is formally used in a discretionary and not in a compulsory sense, it is very often the case, however, that the differences between MAY and SHALL in their performative uses in legal documents are marginal, cf. Words and Phrases Legally Defined, 3rd edition, Vol. 3 and 4 . Hence, despite the fact that the event expressed by be cited in (26) is the main proposition of a modal of deontic possibility rather than necessity, it should be interpreted almost as a compulsion rather than a permission; in this case the law must in actual fact be cited as the Minors' Contracts Act 1987 and not in any other way. 
In (25) may expresses constative deontic possibility of permission, that is, the result/ report of a performative act of giving permission rather than the performative act itself.

In text type I MAY thus expresses either the performative, discretionary MAY of deontic possibility or the constative MAY of deontic possibility / permission which may be seen as a result of the performative use of the same modal. There are no examples of MAY as an epistemic modal or of MAY NOT in this text type.

In text type II (Travaux préparatoires) MAY expresses different subcategories under the modal operator of possibility:

(27) We would point out that consideration need not only consist in promising to pay a sum of money but may also consist in promising to do some other act to forbear from doing something (II)

(28) In time the courts may well reformulate what is now known as the doctrine of substantial performance (II)

(27)-(28) are examples of MAY expressing epistemic possibility. Modals express epistemic modality in relation to "here and now", that is, the time of the utterance, and there is a temporal element of simultaneity and/ or futurity in such modal expressions. This is especially obvious in (28) where the adverbial underscores the futurity feature. All the above examples express a modal proposition "It is possible that $\mathrm{p} "$. They are constative utterances.

MAY also expresses deontic possibility in text type II:

In our working paper (...) we made a provisional recommendation that the sum payable to the party in breach in accordance with the new remedy which was proposed should be reduced, or as the case may be

extinguished by the damages to which the other party may be entitled in respect of the breach of contract (II) 
The first may in (29) (as the case may be) expresses epistemic possibility. The second may in (29) and in (30) express constative deontic possibility, that is, permission as a result of a previous performative act.

As it is seen both in (25) above and in (29)-(30) MAY may express deontic possibility of permission which is interpreted as a result of a performative act of giving permission. This is in contrast to CAN of root possibility which focusses more on the possibility for somebody/thing (or even the ability of the referent of the subject noun phrase) to carry out the event of the main proposition. The distinction which I am trying to make here is admittedly subtle, and one is often faced with indeterminate examples; in spite of that I will still claim that the empirical data lead me to the conclusion that there is typically such a distinction in the corpus data, cf. also example (31):

(31) Under the present law the buyer can refuse to pay, or may recover the price if he has already paid it (II)

I would interpret can in (31) as expressing root possibility and may as expressing constative permission as a result of a previous performative act of giving permission.

Another problem is the indeterminacy between epistemic and root possibility expressed by means of MAY when it is not performative and when the event of the main proposition is a passive verb phrase:

(32) We considered the justification of the present law but we think that it loses the fact that the mischief which we have some of its force in view of not that the parties can require complete performance before 
(33) The situation may be analysed either as a single contract contained in two documents, one of which was inaccurate because inconsistent with the true agreement as reflected in the other (...) (II)

At least out of context, may in both (32) and (33) seems to be indeterminate between epistemic and root possibility. However, a closer look at the context solves the problem in (32) where may is coordinated with will; since the latter no doubt expresses epistemic predictability (prediction), may must also express epistemic modality, i.e. possibility, because it must be assumed that coordinated modals will express either the same modal operator with a difference in the type of modality, or the same type of modality with different modal operators - irrespective of whether they occur in regular binomial expressions or in constructions like the one seen in this example. (33) seems more truely indeterminate.

The central modals can only occur as the operator in a finite verb phrase because of their defective morphology. This does not mean, however, that the main proposition following a modal proposition cannot in itself be modalized; this is seen in (34):

(34) If the parties make a contract which must be in a certain form, it may be contract which is not in that form (II) possible to have a collateral

may expresses epistemic possibility and be possible root possibility in the following proposition. As far as I can see on the basis of the data I have collected, the first modal expression in such examples (in this case may) expresses epistemic modality, whereas the second modal expression (in this case be possible) expresses non-epistemic modality. Hence it is possible by means of an epistemic modal expression to evaluate the truth value of a proposition which is in itself modalized under the condition that the embedded modal proposition is non-epistemic.

There are a few examples with MAY NOT in text type II: 
(35) Our reservation therefore is that the elaborate structure of the present law may not be really necessary to protect minors against the dangers which they face in practice (II)

(36) The second general rule is that contracts made with a minor are binding on the adult party. The minor may enforce them. He may not, however, do so by means of a decree of specific performance (II)

may in (35) expresses epistemic possibility and it is the following proposition that is negated, "It is possible that the elaborate structure of the present law is not really necessary (...)"; in (36) it expresses constative deontic possibility and it is the modal proposition that is negated.

Where non-negated and negated MAY are coordinated, they express the same kind of modality, in (37) and (38) epistemic possibility:

This may, or may not, be true (II)

He may, or may not, have known of the car's true

condition (II)

In text type II we thus typically find MAY expressing epistemic possibility or constative root possibility which is a result of a previous performative act of giving permission. When used in combination with NOT as an epistemic modal, the negation applies to the main proposition; when used as a non-epistemic modal, the negation applies to the modal proposition.

In text type III (Judgments) we find examples such as the following with epistemic MAY: time when the third may erect a house there, I have to party or some other owner of the plot bear in mind that the covenant in the present case is 12 years old and no house has been erected yet nor is there any certainty that one ever will be to the contract specification (III)

(40) Is is perhaps not altogether surprising that the jury may have had some difficulty, for (...) (III) 
As it appears from (39) and (40) examples with epistemic MAY are legio; there are also a few examples with MAY as a constative deontic modal of possibility as in (41):

(41)

As I understand Hyde $v$ Wrench (...) and the cases which have followed, the consequences of placing the order in that way, if I may adopt Megaw J's words (...) was 'to kill the quotation' (III)

(42) Although this is not an occasion for an extended discussion of the decisions in those two cases, Law $v$ Jones (...) appears to have occasioned so much misunderstanding that perhaps I may be permitted to make certain explanatory observations abo I may perhaps add that I see no reason to dissent

from (...) (III)

may in (41) expresses constative deontic possibility of permission, and the same goes for (42) and (43) where the modal element is underscored by other modal elements in the clause; in (42) the passive verb phrase be permitted and the modal adverbial perhaps, in (43) only the modal adverbial; perhaps seems to express epistemic possibility, cf. Perkins (1983:89-93). In contrast to the examples of modal expression + modal expression quoted from text type II above, cf. (34), the two modal expressions in (42), that is, may be permitted seem to express the same modality and can only be interpreted as a means to (politely) underscore the constative deontic modality of the utterance.

(44) I am satisfied from the authorities that the fundamental purpose of the Mareva jurisdiction is to prevent foreign parties from causing assets to be

removed from the jurisdiction in order to avoid the risk of having to satisfy any judgment which may be entered against them in pending proceedings in this country (III)

In (44) there is again an example of indeterminacy between epistemic and non-epistemic possibility where the utterance is constative and the modal is followed by the passive voice in the verb phrase of the main proposition. 
(45) Since 1955 the use of telex communication has been greatly expanded, and there are many variants on it. The senders and recipients may not be the principals to the contemplated contract. They may be servants or agents

with limited authority. The message $\mathrm{r}$

(46) On April 61981 the tenants issued a motion for leave to discontinue their proceedings for a new tenancy. RSC Ord 21, r 3, provides that, with exceptions not here material, a party may not discontinue an action,

whether begun by writ or otherwise, v

As it appears from (45) and (46), NOT in combination with epistemic MAY again results in a negation of the main proposition, in combination with deontic MAY a negation of the modal proposition.

In text type III, then, MAY occurs as en epistemic modal of possibility or constative deontic modal expressing permission as a result of a previous performative act. Where epistemic MAY occurs in combination with NOT, it is the main proposition which is negated, where deontic MAY occurs with NOT, the modal proposition is negated.

The following examples stem from text type IV (Contracts):

(47) The plant shall be under the control of the Hirer at all times from delivery

shall ensure that the plant is used safely until re-delivery and the Hirer

risk to health, is used by competent and duly licensed and without

operators as the case may be and is nı 
(48) The company may deduct from the employee's remuneration the amount of any sickness benefit payment to which the employee shall be entitled by reason of such absence under the social security legislation for the time

(49) The employee agrees to advise the company of his whereabouts so that he may be reached at any reasonable time and the employee agrees to serve the company exclusively at all times required by the company.(IV)

In (47) may expresses epistemic possibility, in (48) performative deontic possibility ("The company may at its discretion deduct ...") and in (49) constative deontic possibility ("It is possible for X/ the company to reach the employee (...)"); in the following examples, MAY is negated (which is rare in text type IV):

(50) If, in the opinion of the Company, the Distributor's financial condition at any time may not justify continuance of the work to be performed by the Company hereunder on the agreed terms of payment, the Company may require full or partial payment in advance (...) (IV)

(51) The purchaser may not transfer his licence or authorise any other person save members of his immediate family to occupy any part of the property (IV)

The data only supply examples of NOT in combination with epistemic MAY where the main proposition is negated as in (50) or with performative deontic MAY where the modal proposition is negated as in (51).

In text type IV MAY is thus used in all the modal subcategories we have seen so far: epistemic possibility, performative deontic possibility (performing the act of giving permission at the discretion of the agent carrying out the event of the main proposition), or constative deontic possibility which is typically a result of a previous performative act of granting permission. In order to determine whether MAY expresses performative or constative deontic possibility, one must take into consideration the non-linguistic element of sender-receiver relations in combination with the immediate linguistic 
context. Epistemic MAY NOT negates the event of the main proposition, whereas deontic MAY NOT negates the modal proposition.

\section{Conclusion}

In the above I have accounted for the use of the modals CAN and MAY in the four text types 1 . Statutes, rules and regulations, 2. Travaux Préparatoires, 3. Judgments, and 4. Contracts. In each case it was indicated whether the modals formed part of a constative or a performative utterance and, in cases of negation, whether the modal or the following main proposition was negated. The use of these two modals which (together with their past tense counterparts COULD and MIGHT, cf. Lauridsen (in preparation)) express the modal operator of possibility, may be summarized as follows: of the two, only MAY expresses epistemic possibility. Deontic possibility may be subdivided into at least three categories: A performative deontic possibility by means of which permission is granted and a constative deontic possibility of permission which is the result of a previous performative act; these two subcategories are expressed by means of MAY. The interpretation of MAY as performative or constative in such cases relies heavily on the immediate linguistic context as well as the situational context of especially sender-receiver relations. Constative deontic possibility which is also termed root possibility is typically expressed by means of CAN and so is the dynamic possibility, also termed ability.

It must be stressed again that these categories should be regarded as Boolean, and there are numerous examples of indeterminacy between them, especially between epistemic and non-performative deontic MAY and between constative deontic possibility (root possibility) and 
dynamic possibility (ability). There are a few cases of indeterminacy between epistemic and dynamic CAN.

In this paper I have focussed on the meaning and use of MAY and CAN in positive and negative clauses and on the semantic and, to a certain extent, functional distinction between the two. There are obviously a whole range of problems which I have not been able to discuss in such a relatively short paper; among these are the semantic relations between CAN and MAY and their past tense counterparts COULD and MIGHT, or the semantic relation between the so-called discretionary MAY and the mandatory SHALL of legal discourse. As far as speech act theory is concerned, I have assumed without discussion that the texts are master speech acts (cf. Fotion (1971) and Kurzon (1986)), that is, that the text as a whole forms a superordinate speech act within which is embedded a range of subordinate speech acts. As a general rule, a master speech act determines the kinds of subordinate speech acts acceptable within itself. Space does not permit an elaboration of this point here; there is no doubt, however, that further functional analyses can throw more light on the meaning and use of the modals in legal and all other types of discourse.

\section{References}

Austin, J. L. (1962/1975), How To Do Things With Words, 2nd ed. Oxford: Oxford University Press.

Bjarkman, Peter C. \& Victor Raskin (eds) (1986), The Real World Linguist: Linguistic Applications in the 1980s. Norwood, N.J .: Ablex.

Coates, Jennifer (1983), The Semantics of the Modal Auxiliaries. London / Sydney / Dover, New Hampshire: Croom Helm.

Crystal, David \& Derek Davy (1969), Investigating English Style. English Language Series. London: Longman.

Danet, Brenda (1980), Language in the Legal Process. In Law \& Society Review, Vol. 14, \#3, pp 447-556. 
Danet, Brenda (1984), Introduction. In Text 4 (1-3), pp 1-8.

Danet, Brenda (1985), Legal Discourse. In Dijk, Teun A. van (ed.) (1985), pp 273-291.

Davidsen-Nielsen, Niels (1990), Tense and Mood in English. A Comparison with Danish. Berlin / New York: Mouton de Gruyter.

Dijk, Teun A. van (ed.) (1985), Handbook of Discourse Analysis. Vol. 1. Disciplines of Discourse. London / Orlando / San Diego / New York / Toronto / Montreal / Sydney / Tokyo: Academic Press.

Fotion, N. (1971), "Master Speech Acts". In Philosophical Quarterly, 21, pp 232-243.

Gustafsson, Marita (1984), The syntactic features of binomial expressions in legal English. In Text 4 (1-3), pp 123-141.

Johansson, Stig et al. (1978), Manual of information to accompany the Lancaster-Oslo/Bergen Corpus of British English, for Use with Digital Computers. Department of English, University of Oslo.

Kurzon, Dennis (1986), It Is Hereby Performed .... Explorations in Legal Speech Acts. Amsterdam / Philadelphia: John Benjamins.

Kurzon, Dennis (1989), Language of the Law and Legal Language. In Lauren, Christer \& Marianne Nordman (eds) (1989), pp 283-290.

Lauren, Christer \& Marianne Nordman (1989), Special Language. From Human Thinking to Thinking Machines. Clevedon, Philadelphia: Multilingual Matters Ltd.

Lauridsen, Karen M. (1988), Overvejelser omkring principperne for en syntaktisk semantisk kontrastiv analyse af modalverberne i moderne engelsk og dansk. In Hermes 1-1988, pp 133-151. Det erhvervssproglige Fakultet, Handelshøjskolen i Århus.

Lauridsen, Karen M. (in print), Principles for Syntactico-Semantic Contrastive Analysis of the Modal Verbs in English and Danish. In Papers and Studies in Contrastive Linguistics, vol XXVII. Poznán, Adam Mickiewicz University.

Lauridsen, Karen M. (in preparation), A Contrastive Study of the Meaning and Use of the English and Danish Modals.

Leech, Geoffrey N. (1987), Meaning and the English Verb. 2nd ed. London: Longman.

Levi, Judith N. (1986), Applications of Linguistics to the Language of Legal Interactions. In Bjarkman, Peter C. \& Victor Raskin (eds) (1986), pp 230-265. 
Lyons, John (1977), Semantics, vol II. Cambridge: Cambridge University Press.

Maley, Yon (1987), The language of legislation. In Language in Society 16, pp 25-48.

Palmer, F.R. (1986), Mood and Modality. Cambridge Textbooks in Linguistics. Cambridge: Cambridge University Press.

Palmer, F.R. (1988), The English Verb. 2nd ed. London: Longman.

Palmer, F.R. (1990), Modality and the English Modals, 2nd ed. London: Longman.

Perkins, Michael (1983), Modal Expressions in English. London: Frances Pinter.

Prior, A.N. (1957), Time and Modality. Being the J ohn Locke Lectures for 1955-6 delivered at the University of Oxford. Oxford: The Clarendon Press.

Rescher, N. (1979), Leibniz: An Introduction to his Philosophy. Oxford: Basil Blackwell. 